\title{
A INVENÇÃO DO ÍNDIO
}

FRANCIS MARY SOARES CORREIA DA ROSA ${ }^{1}$

UEFS

RESUMO: Esta trabalho trata-se de uma investigação sobre os procedimentos históricos que essencializaram e normatizaram categorias sígnicas, notadamente inventadas dentro de um discurso colonial, forjando identidades étnicas sobre os povos ameríndios. Por meio de uma revisão teórico-conceitual crítica, busca-se reconhecer a historicidade dos processos de classificação, bem como revisar a visão eurocêntrica sobre o processo de conhecimento. Esperase contribuir para o debate crítico sobre os processos de nomeação, assim como para a descolonização das subjetividades por meio do processo de etnogêneses dos povos ameríndios.

PALAVRAS-CHAVE: indígenas; etnogênese; crítica cultural.

ABSTRACT: This paper aims at investigating the historical procedures that worked to standardize and essentialize sign categories, which were notably invented within a colonial discourse that imposed ethnic identities on Amerindian peoples. By means of a critical theoretical review of concepts it shows the historicity of the classification processes, thus rejecting a Eurocentric vision of the knowledge process. In that way, I hope to contribute for the theoretical debate on the naming process, as well as for the decolonization of subjectivities through the ethnogenetic process of Amerindian peoples.

KEYWORDS: indigenous; ethnogenesis; critical studies.

Parece-me gente de tal inocência que, se nós entendêssemos a sua fala e eles a nossa, eles se tornariam logo cristãos, visto que não aparentam ter nem conhecer crença alguma Pero Vaz de Caminha (1999, p. 12).

\footnotetext{
${ }^{1}$ Mestranda em Crítica Cultural - Universidade Estadual da Bahia-UNEB; professora do Departamento de Ciências Humanas e Filosofia da Universidade Estadual de Feira de Santana-UEFS; pós-Graduada em Filosofia Contemporânea - UEFS e Ensino de Filosofia -UFBA; Graduada em História-UNEB e graduanda em Filosofia - CEUCLAR; membro do grupo de pesquisa Lingua(gem) e Crítica Cultural na linha Literatura, subalternidade e micropolítica (UNEB). E-mail: francismrosa@ hotmail.com .
} 
O termo "índio2" apresenta-se na historiografia brasileira como uma espécie de eco que ressoa por mais de 500 anos, desde que aqui se iniciou um determinado processo de colonização e constituição histórica de identidades sociais. Índios e negros são classificações inventadas, forjadas em meio a uma estrutura sígnica, e essencializadas para que resguardassem distintas categorias de tipificação baseadas no pressuposto da raça e em uma determinada forma de escrita das outridades.

Para o historiador Leandro Karnal (2004), os europeus construíram uma representação do termo "índio" por meio do equívoco geográfico de Colombo, que registrou erroneamente a sua chegada às Índias. Esse "equívoco", como adverte Karnal, foi normatizado no seio de um discurso sobre raça que se formava e imbricado a uma construção hierárquica de valores que, por sua vez, foram respaldados em uma dada suposição de diferenças biológicas, psíquicas e intelectuais entre os indivíduos. Para Quijano (2005), a ideia de raça, oriunda dessas novas identidades sociais, estabeleceu-se em concomitância com o modelo de dominação econômica que se fortalecia com o andamento do projeto colonial, ao mesmo tempo que the garantia legitimação.

Segundo Quijano (2005), nesse contexto, nomes como Europa e América, que diziam muito mais sobre a posição geográfica (e mesmo sob este prisma, o conceito é relativo), tiveram incrementados aos seus valores sígnicos o status relacional de subalternização presentes na conquista e naturalização da ideia de superioridade por meio dos embates de dominação ocorridas entre europeus e não europeus. Tal perspectiva, aliada aos avanços e expansão da colonização europeia sobre o mundo, conduziram o fortalecimento de uma visão eurocêntrica sobre o processo de conhecimento, assim como a colocação da Europa e toda sua produção intelectual, política, estética, etc. como eixo do globo. De acordo com Quijano:

[...] os povos conquistados e dominados foram postos numa situação natural de inferioridade, e consequentemente (sic) também seus traços

\footnotetext{
${ }^{2}$ Notadamente, segundo Carneiro da Cunha (2009, p. 183), a palavra "índio" começa a ser empregada em meados do século XVI para designar os indígenas submetidos em contraposição ao termo mais geral, "gentio", que designa os indígenas independentes. Pela metade do século, segundo a autora, usa-se concomitantemente a expressão "negro da terra".
} 
fenotípicos, bem como suas descobertas mentais e culturais. Desse modo, raça converteu-se no primeiro critério fundamental para a distribuição da população mundial nos níveis, lugares e papéis na estrutura de poder da nova sociedade. Em outras palavras, no modo básico de classificação social universal da população mundial (QUIJANO, 2005, p. 229).

Essas consequências repercutiram na formação do imaginário não somente daqueles que eram lidos como conquistadores/dominadores, como também na própria configuração e na formação da identidade das populações tidas como conquistadas/dominadas. O termo imaginário, ao qual faço referência, deve ser entendido na perspectiva de Glissant (2005, p. 21-27), que entende que o imaginário diz respeito ao processo pelo qual ocorre a percepção e a formação da totalidade das relações humanas no que tange à literatura, à política, à cultura, à história e a tantos outros campos e enunciados discursivos sobre o conhecimento e formação das identidades, promovendo variações, "microclimas" e "macroclimas" (GLISSANT, 2005, p. 21) que respondem por constituir. em momentos distintos da história, ora unicidades, ora variações e/ou relações.

Assim, no período histórico em que ocorreram o processo de colonização e suas etapas subsequentes no território que os europeus nomearam de Brasil, uma ideia de raça atrelada a um discurso racista e eurocêntrico - que não se restringe ao mundo colonial - forjou um certo imaginário identitário sobre os povos nativos da América e outras identidades diaspóricas.

Ser nomeado de índio, negro, asiático etc. se constituía como categorias raciais que naturalizavam valores historicamente constituídos que tinham como base um regime de verdade que reservava à Europa um certo olhar que lhe garantia uma dada superioridade ontológica e universal sobre os valores políticos, morais, culturais, econômicos, etc. dos outros povos. Para Shohat e Stam:

As categorias raciais não são naturais ou absolutas: são construções relativas e específicas, categorias narrativas engendradas por processos históricos de diferenciação. A categorização de uma mesma pessoa pode variar com o tempo, o local e o contexto. Também a autodefinição subjetiva e a mobilização política podem sabotar definições. Os africanos, antes da colonização, não pensavam em si mesmos como negros, mas como 
membros de grupos específicos - bantu, fon, haugá, ibo - assim como os europeus, antes da invenção do 'branco', consideravam-se irlandeses, sicilianos e assim por diante (SHOHAT e STAM, 2006, p. 46).

Por mais que um historicismo sobre as categorias de raça se desdobre em tempos posteriores ao início do projeto colonizador e incorra em variações de acordo com a região colonizada, como destaca Walter Mignolo (2005), o que se torna evidente e aproxima histórica e discursivamente todo o universo nativo é a situação de inferioridade com que tais grupos foram tratados em relação aos colonizadores:

A mediados del siglo XVI, Las Casas proporcionó una clasificación racial aunque no tuviese en cuenta el color de la piel. Era racial porque clasificaba a los seres humanos en una escala descendente que tomaba ideal es occidentales cristianos como criterio para la clasificación. La categorización racial no consiste simplemente en decir "eres negro o indio, por tanto, eres inferior", sino en decir "no eres como yo, por tanto eres inferior" (MIGNOLO, 2005, p. 43 - grifos no original).

Essa perspectiva nos coloca diante de um revisionismo em relação ao termo "índio" que foi amplamente naturalizado nos discursos oficiais e que, equivocadamente, foi atribuído às mais de mil nações ${ }^{3}$ que existiam no território nomeado de Brasil. Segundo Almeida (2010), a nomeação da extensa diversidade de povos que habitavam o território ocorreu por critérios europeus e atendia aos objetivos e funcionalidades do projeto colonizador. As classificações que eventualmente fugiam do monômio "índio" recaíam, por sua vez, no binômio tupi/tapuia, que dizia respeito ao sistema de alianças que ocorria entre portugueses e os aliados nativos, tradicionalmente descritos e referenciados como "tupi", ao passo que todos aqueles que não eram "tupi", se tornavam "tapuia", que, na língua tupi, quer dizer bárbaro.

O processo de conquista europeu foi seguido de perto por articulações discursivas preconceituosas que degradavam sistematicamente o modo de vida e a cultura dos nativos americanos. $O$ próprio imaginário europeu, como destacam Shohat e Stam (2006, p. 97), serviu de base para a transposição de todo um aparato ideológico sobre 
o outro para as Américas, em que os velhos medos e a demonologia europeia se articularam na formação de uma imagem estereotipada e preconceituosa sobre os nativos. De acordo com Shohat e Stam:

A demonologia européia [sic] cristã deu o tom do racismo colonial. Na verdade, um aparato ideológico antigo foi "reciclado" nas Américas. As narrativas de Américo Vespúcio sobre suas viagens, por exemplo, serviam-se do estoque de estereótipos judeus e de imagens fantasmagóricas para caracterizar os povos nativos da América como selvagens, infiéis e promíscuos: ou "bebedores de sangue", "canibais", "bruxos" e "demônios" (SHOHAT e STAM, 2006, p. 97).

Assim, se na Europa a demonologia relacionava-se às bruxas, judeus e mulçumanos, identificados como uma espécie de extremo oposto daquilo que era legitimado como socialmente válido e desejado, a demonologia instalada na construção de uma alteridade ameríndia baseava-se, indubitavelmente, na negação. Essa visão fica claramente projetada na frase de Pero de Magalhães Gândavo no Tratado da Terra do Brasil, de 1573, onde destaca: "A língua deste gentio toda pela costa é uma: carece de três letras - scilicet, não se acha nela $F$, nem $L$, nem $R$, coisa digna de espanto, porque assim não tem Fé, nem Lei, nem Rei; e desta maneira vivem sem Justiça e desordenadamente" (GÂNDAVO, 1980, p. 14). Por meio das ideias de falta e ausência, nomeava-se e classificavase a outridade "ameaçadora" por meio do repertório próprio do acervo cultural então presente no imaginário europeu, que, de forma geral, repercutia uma visão negativa e despojada de humanidade sobre os ritos e religiosidades ameríndias. Conforme Laura de Mello e Souza (1993, p.25):

Se a descoberta de novos mundos pôde revigorar os símbolos do maravilhoso, foi capaz também de fortalecer a demonologia européia. Mundo inquietante, capaz de seduzir e aterrorizar ao mesmo tempo [...] o ultramar atlântico provocava vertigens no europeu do século XVI, impelindo-o a buscar referências em contextos tranquilizadores, 'concretos ou mentais - pouco importa'. Recuperam-se então mitos familiares e muitas vezes antigos, que, 'enxertados em húmus diverso', ajudam a compreender os enigmas do mundo, 'transformando-se em instrumentos de conhecimento 
dentro de um horizonte de significação' (MELLO E SOUZA, 1993, p. 25).

Dessa forma, a ideia de "índio" atendia muito mais a uma nomeação generalizada dos colonizadores para as nações e grupos étnicos que viviam no chamado "novo mundo" do que propriamente a uma autonomeação por partes dos povos nativos. Dizia muito mais a respeito da forma como os europeus que aqui se instalaram viam uma dada outridade e da maneira como esse outro foi posto em contato com o projeto colonial, a saber, negando sua especificidade humana, língua, cultura e cosmovisão.

Contudo, é preciso observar que, se houve um processo de inscrita e sobreposição da imagem dos ameríndios à ontologia e à cosmovisão europeias, a documentação oficial nos leva a identificar que a negação e desconhecimento de sua humanidade não estava associada à falta da existência desta. Pois, como atesta Carneiro da Cunha (2009, p. 191), por mais que haja dessemelhanças e diferenças, a humanidade indígena 4 é atestada e reconhecida, porém atravessada pela cosmologia europeia, mais especificamente portuguesa, francesa e espanhola, que se desdobram em ratificar uma origem comum de uma dada humanidade prioritariamente alicerçada na visão cristã e encabeçada pela orientação de tornar legível esse outro, mesmo que direcionada pelo imperativo de entender a si mesmo em meio às mudanças e rupturas de paradigmas do século XVI. Para Carneiro da Cunha:

Com o Novo Mundo descobre-se também uma Nova Humanidade. Resta o problema crucial de inseri-la na economia divina, o que implica incluí-la na genealogia dos povos. Para isso, não há outra solução senão a da continuidade, senão abrir-lhes um espaço na cosmologia europeia. Por que a humanidade é uma só, os habitantes do Novo Mundo descendem necessariamente de Adão e Eva, e portanto de um dos filhos de Noé, provavelmente do maldito, Cam, aquele que desnudou seu pai... (CARNEIRO DA CUNHA, 2009, p. 191).

\footnotetext{
${ }^{4}$ Um dos documentos comprobatórios do reconhecimento dessa humanidade é a Bula Veritas Ipsa, emitida pelo Papa Paulo III, em 29 de maio de 1537, declarando que os índios eram homens e que, como tais, tinham alma.
} 
Para Daniel Munduruku (2009, p. 19-22), o reconhecimento da humanidade dos coletivos nativos não representou de fato a incrementação de uma política e postura mais "humanizada" por parte dos colonizadores no trato e relacionamentos firmados até então. A perspectiva, segundo o autor, da suposta civilidade e superioridade europeias repercutiu em uma postura de práticas de violência física e simbólicas que operaram um verdadeiro genocídio entre os nativos brasileiros, considerados "selvagens" e "bárbaros".

Como destaca Eni P. Orlandi (2008), desde que a ideia de "descobrimento" foi difundida, operou-se um processo relacional nos planos político social, científico (a ciência torna o indígena observável e tipificado), cultural e religioso, em que a diferença e, acima de tudo, a própria existência indígena é sistemática e violentamente apagada ou inviabilizada. Essa premissa do "vazio" garante a legitimidade de uma construção imagético-discursiva que potencializa o decalque da Europa para o chamado "Novo Mundo", silenciando e inviabilizando os sujeitos históricos que aqui se encontravam.

Observa-se que essa leitura essencialista sobre a identidade nativa garantia uma visão homogeneizadora sobre essa outra humanidade que era legitimada pelas relações sociais e de poder instituídas no universo colonial. Essa perspectiva preconizou um certo protótipo de identidade alicerçada no modelo europeu, que se constituía na composição de um projeto civilizatório que se caracterizava majoritariamente por marginalizar possíveis variantes a uma condição bestializada, inacabada e inferior. Diante disso, o conceito de índio foi forjado por um conjunto de enunciados discursivos alheios à própria esfera da autodenominação nativa.

Transformados em objetos, mais de mil nações ou grupos nativos foram reduzidos a um estereótipo e ao dualismo etnocêntrico tupi/tapuia. Segundo Carneiro da Cunha, a imagem dos grupos nativos ocorre substancialmente espelhada numa visão sobre "a dos grupos de língua tupi e, ancilarmente, guarani. Como em contraponto, há a figura do Aimoré, Ouetaca, Tapuia, ou seja, aqueles a quem os Tupi acusam de barbárie" (CARNEIRO DA CUNHA, 2009, p. 180).

É por uma ótica externa relacionada à Europa, alienígena a sua cosmovisão, que os grupos nativos americanos surgem como categoria e 
formulação identitária. O termo "índio" insere-se em um discurso que faz da palavra um atributo, um artifício sígnico de domesticação, em que todas as diferenças e particularidades se desfazem em meio, e contrapondo-se, ao discurso universalista do homem branco, civilizado, letrado e cristão. Para Janice Thiél:

Nomear é prática política que estabelece uma relação de poder. O colonizador inventa o índio, rotulado por um discurso homogeneizador, que ainda persiste no século XXI. Pelo seu discurso, submete a existência e caracterização do índio a quadros de referência europeus. [...] Visto como folha em branco, o nativo é classificado como uma nova espécie que é descoberta e incorporada ao universo do conhecimento europeu (THIÉL, 2012, p. 18).

É em meio a esse processo de construção e elaboração de etnônimos exógenos instaurados nos interesses da conquista que a formulação de uma outra identidade se constituiu. Se de início a nomeação era alienígena, o contato entre populações nativas e europeias propiciou um deslocamento e reterritorialização de tais epítetos, sendo inclusive tais identificações utilizadas pelos próprios nativos de forma a postular novas relações na dinâmica colonial (CRUZ e RESENDE, 2015). Dessa forma, o contato com o europeu incidiu sobre a maneira que tais populações se viam e se autoidentificavam.

\section{O conceito de índio: variações}

Se por um dado período de tempo o termo índio foi utilizado de forma domesticadora e desprovida de sentido identitário por aqueles que recebiam tal epíteto, é no século $X X$, mais precisamente em meados da década de 80 , após uma longa luta por conquistas de direitos, que os povos indígenas se apropriam do nome imposto pelas práticas coloniais e forjam uma unidade, ao menos sígnica, para assegurar representatividade e os alicerces de um outro paradigma identitário. $\mathrm{O}$ termo "índio" é apropriado por lideranças do movimento indígena brasileiro e utilizado como elemento de representação política e aglutinador de identidades étnicas distintas, mas que compactuavam uma 
mesma cosmovisão e uma situação subalternizada na sociedade brasileira.

O conceito de identidade étnica aqui aludido diz respeito à concepção trazida por Poutignat e Streiff-Fenart (2011, p. 84), que defendem a autodefinição baseada em pressuposto subjetivos como elemento-chave para a compreensão das diferenças e mecanismo de autorrepresentação por parte dos indivíduos que agem como grupos étnicos distintos e reconhecem-se como pares comuns em sua pertença étnica. Nos casos dos grupos indígenas, tal percepção ganha destaque pelo fato de que, por muito tempo, a presença do olhar exógeno contribuiu para a constituição e denominação dessas identidades. Maria Regina Celestino Almeida (2010, p. 34) traz, por exemplo, a informação de que as identidades étnicas que foram tradicionalmente nomeadas pelos cronistas, em sua maioria, não são categorias fixadas, mas correspondem a nomeações exógenas ou mesmo imbricadas em processos mútuos de câmbios ou trocas culturais:

Assim, as identidades étnicas apontadas pelos cronistas não devem ser vistas como categorias fixas, uma vez que muitas delas devem ter sido criadas a partir das situações vivenciadas pelos índios e pelos portugueses. Em Pernambuco, por exemplo, os portugueses aliaramse ao grupo por eles chamado tabajara, termo usado em tupi para designar os inimigos da mesma origem ou inimigos cunhados que podiam ser aprisionados nas guerras. No Rio de Janeiro, os temiminós tornaram-se conhecidos a partir das relações amistosas com os portugueses, com os quais se aliaram na luta contra os tamoios. [...] Tabajaras e temiminós podem, pois, ter passado a existir como etnias a partir do contato com os portugueses. Estudos recentes têm demonstrado que essas recriações identitária podiam servir também aos interesses dos índios, que souberam adotá-las e utilizalas ao seu favor, como se verá a seu tempo (ALMEIDA, 2010, p. 34-35, sic).

Para Frederick Barth (2011, p. 189-199), um grupo não se autoidentifica de forma isolada, sem a presença de interação social. Para o autor, o sentimento de pertença étnica é reelaborado e instituído de forma dinâmica por meio de processos endógenos e exógenos, não evitando, contudo, que ocorram casos em que a nomeação exógena se 
sobreponha a todos os processos de etiquetagem e rotulações internas. Segundo Frederick Barth (2011, p. 195), além das relações culturais, a maneira como politicamente tal sentimento de pertença étnica se insere dialeticamente nas relações sociais de apropriações e ressignificações é permeado por uma relação de alteridade concebido em meio ao que o autor nomeou de "fronteira étnica", em que a ideia de identidade étnica perpassa pelo estabelecimento, manutenção e ressignificação de forma fluída dessas fronteiras balizadas pelas diferenças culturais:

As fronteiras às quais devemos consagrar nossa atenção são, é claro, as fronteiras sociais, se bem que elas possam ter contrapartidas territoriais [...] Os grupos étnicos não são simplesmente ou necessariamente baseados na ocupação de territórios exclusivos. Além disso, a fronteira étnica canaliza a vida social - ela acarreta de um modo frequente uma organização muito complexa das relações sociais e comportamentais. A identificação de outra pessoa pertencente a um grupo étnico implica compartilhamento de critérios de avaliação e julgamento. [...] Assim, a persistência de grupos étnicos em contato implica não apenas critérios e sinais de identificação, mas igualmente uma estruturação da interação que permite a persistência das diferenças culturais (BARTH, 2011, p. 196).

É em meio a essa perspectiva que Daniel Munduruku (2012, p. 3337) exalta a importância da reapropriação política, no final do século XX, do termo "índio" por parte do movimento indígena brasileiro, que buscava, entre outros horizontes, garantir a construção de outras relações entre os grupos nativos e a sociedade brasileira. $\mathrm{O}$ autor nos lembra que até meados da década de 50, o termo "índio" era ostensivamente rejeitado pelas comunidades nativas por estar permeado de uma carga altamente pejorativa, visto que no período de atuação do projeto colonizador, assim como na época posterior, nos séculos XVIII a $\mathrm{XX}$, a nomenclatura "índio" objetivava rotular e dissipar as diferenças, diluindo-as no repertório cultural do colonizador.

A constituição de uma identidade partilhada entre as populações nativas sobre o signo do termo "índio" visava estabelecer entre povos de culturas específicas o sentimento de coletividade e compartilhamento de memórias comuns. Tal proposta respaldava-se no caráter de negar uma 
postura assimilacionista que pregava um suposto e inevitável fim das populações nativas por meio do processo de aculturação e negação de sua autonomia.

Para Maria Regina C. Almeida, essa visão de que os indígenas estavam inevitavelmente fadados a se integrar na sociedade nacional destituindo-se de sua cultura ancestral foi o viés ideológico que percorreu a maioria das políticas públicas desde o século XVIII:

A política assimilacionista para os índios, iniciada com as reformas pombalinas em meados do século XVIII, teve continuidade no Império brasileiro e também na República. Ainda que diferentes legislações garantissem as terras coletivas e alguns outros cuidados especiais para os índios enquanto eles não fossem considerados civilizados, a proposta de promover a integração e extingui-los como grupos diferenciados iria se manter até a constituição de 1988 (ALMEIDA, 2010, p. 18).

Para Alcida Ramos, esse engajamento por parte das comunidades indígenas ocorreu frente ao projeto do presidente Geisel, em 1978, que ameaçava a condição dos povos nativos de tutelados pelo estado ao prever a emancipação indígena, o que significaria "eximir-se do encargo de protegê-los, juntamente com suas tradições, seus usos e costumes e, o mais importante, suas terras" (RAMOS, 1995, p. 5). Segundo a autora, esse foi o primeiro momento do que ficou conhecido como panindianismo, que se caracteriza justamente por possuir o viés aglutinador das etnias em torno da ideia de índio, então legitimado socialmente e legalmente.

Tal momento representou a configuração do que autora nomeia como "índio hiper-real". Baseando-se na definição de simulacro de Jean Baudrilliard, em que a simulação postula objetos sígnicos sem referência, precedente ao real e que tomam de assalto a esfera da realidade, tornando-a um modelo hiper-real, além da própria realidade: "A simulação já não é a simulação de um território, de um ser referencial, de uma substância. É a geração pelos modelos de um real sem origem nem realidade: hiper-real" (BAUDRILLARD, 1991, p. 8). Alcida Ramos destaca que o simulacro sobre a ideia de índio instaura um regime sígnico que opera como aperfeiçoamento ou, no que foi tematizado pela autora, como uma adequação, no caso brasileiro, ao modelo de burocratização 
organizacional defendido pela lógica moderna do escritório, consagrada nos estudos de Max Weber, visto que é nesse contexto que organizações diversas de apoio à causa indígena tematizam os índios como sujeitos de direito:

\begin{abstract}
O que fazer com a alteridade dos índios, tão pouco afeita à domesticação da lógica do bureau? Como controlá-la e torná-la compatível com os "propósitos impessoais e funcionais" da organização burocrática? Como contornar - descompasso entre a ânsia organizacional das entidades e a necessidade de atuar na interface entre políticas indígenas e políticas brancas? A "vocação" weberiana do escritório não poderia ser menos apropriada para lidar com a questão interétnica. Então, para cumprir o destino ocidental da burocratização e, ao mesmo tempo, lidar com questões indígenas, a saída parece ter sido inventar um índio "burocratizável". Os índios "de carne e osso" começam a ser filtrados, sua alteridade indomada, criadora de desordem em potencial ou de fato para as entidades, sofre um processo de domesticação e surge então um modelo de índio, que seria uma espécie de "índio-modelo" (RAMOS, 1995, p. 12).
\end{abstract}

Nesse contexto, a eclosão do movimento indígena sugere uma atividade relacional de imbricação de sua identidade intersubjetiva aos espectros e prospectos do estereótipo até então atribuído a uma gama de diferentes culturas e de diversidades de pertenças étnicas. Essa preocupação de normatizar e postular identidade fixadas, cuja legitimação repousa na necessidade organizacional do modelo de estado em categorias políticas e institucionais, contribuiu para o reforço da crença em um perfil homogêneo e estático sobre as culturas indígenas.

Dessa forma, em momentos distintos da história, os grupos nativos das mais diversas pertenças étnicas remodelaram e se apropriaram dos etnônimos, de sua própria identidade e de um sentimento comum de pertencimento a uma fraternidade maior do que seu próprio grupo étnico ou comunidade. Como destaca Barth (2011), é por meio do contato e interação com os "outros" que é possível a manutenção de uma dada identidade étnica entre grupos e seus membros. É exatamente por se identificarem enquanto "índios" em contraponto aos não índios que o movimento pan-indígena promoveu um imperativo de reflexões críticas 
e políticas sobre o lugar e o papel dos grupos indígenas frente ao poder constituído.

Essa perspectiva é destacada por Daniel Munduruku (2012), que sistematiza a importância e a contribuição dessa formação e afirmação identitária, a saber, a apropriação do termo "índio" em meio a um imaginário nacional que era continuamente bombardeado por uma política de assimilação que silenciava e negava a existência dos povos nativos ou lhes reservava o destino fatídico da incorporação, promovida com o epíteto de "aculturação", em que tal palavra resguarda em seu conceito a ideia de superioridade da cultura europeia frente a uma suposta imobilidade e "engessamento" das comunidade indígenas.

O "aculturado" é aquele que foi destituído de sua cultura em detrimento de outra, que não mais professa uma suposta identidade pura e original, pois só é reconhecido em sua identidade na condição de isolado culturalmente. Essa perspectiva vinculava-se a uma simplificação hierarquizante das culturas, assim como seu entendimento em categorias estáticas e uniformes (PAIVA, 2015, p. 148). Tal visão difundia a imagem de um indígena estratificado e impossibilitado de inserir-se no projeto da nação brasileira.

Para Daniel Munduruku:

[...] o Movimento Indígena alimentou, por tempo considerável, um projeto educativo que caminhava em duas direções: a da formação de quadros para sua continuidade e a da formação da sociedade brasileira para a existência de diferentes povos indígenas brasileiros (MUNDURUKU, 2012, p. 39).

Neste sentido, percebe-se que os fundamentos para novos deslocamentos e apropriações que o termo "índio" encontrou no Brasil, diferentemente do que ocorreu na maior parte da América chamada de latina, em que o termo figura como altamente depreciativo, ganhou ares de resistência e empoderamento nos embates produzidos pelo movimento indígena, servindo de expediente para invocar um sentido de aliança intercomunal entre os indígenas (GUZMÁN, 2013).

\section{O conceito de índio: relações e dinâmicas contemporâneas}


Posso ser quem você é, sem deixar de ser o que sou Marcos Terena (2003, p. 104).

Durante as décadas anteriores aos anos 90, a reinvenção e apropriação como estratégia política do etnônimo "índio" serviu como veículo para sustentar e fomentar uma pan-indianidade no cenário político nacional até a constituição de 1988, contribuindo para a instauração de novas formas de relações políticas entre o estado-nação brasileiro e as comunidades indígenas.

No entanto, é no final do século XX que lideranças indígenas começam a questionar a validade e a continuidade de tal epíteto para designar a imensa gama de diferenças culturais e de pertenças étnicas, pois, como o texto constitucional de 1988 determinava a demarcação das terras indígenas no próximo quinquênio, assim destaca Daniel Munduruku (2012), era preciso uma "retirada estratégica" de uma bandeira mais geral para dar voz às questões regionais e os anseios e particularidades de cada comunidade.

Dessa forma, a configuração legal de um sujeito indígena brasileiro ${ }^{5}$ presente na constituição de 1988 repercutiu em outras formas de autoidentificação que se inserem de forma relacional ao etnônimo "índio". Ao invés de apenas se identificarem como "indígenas" ou "índios", as comunidades passaram a declarar suas pertenças étnicas, não somente entre os grupos indígenas, fato que já ocorria, mas também no próprio processo de representação nacional ou na sua apresentação aos não índios. Assim, o nome, elemento fundamental na maioria das culturas indígenas, como destaca Brighenti (2015), tem uma importância fundamental no universo existencial dos indivíduos indígenas, pois denota sua função social e destaca-se como elemento aglutinador de sua personalidade.

É por meio do reconhecimento do nome indígena e de seu povo que uma outra representação no imaginário nacional sobre o indígena vai sendo alicerçada. De caráter fluido, tal processo identitário coaduna-se como parte integrante da constituição de um modelo autorrepresentativo baseado na diferença ativa, passo fundamental, de acordo com Viveiros

\footnotetext{
${ }^{5}$ A constituição de 1988 enfatiza o reconhecimento legal do indígena no estado brasileiro, assim como garante sua cidadania plena e o direito a cultura e organização social próprias.
} 
de Castro (1983), para a construção e o fortalecimento de um protótipo de cidadania de caráter transnacional em contraponto à cidadania monolítica proposta no Brasil. Tal proposta de cidadania e o ideário presente na epígrafe do tópico demonstram o esforço, por parte dos grupos indígenas, de desenvolverem estratégias que mobilizem ou permitam a alocação de suas identidades ao cenário hegemônico nacional.

Longe de uma perspectiva isolacionista, essa composição híbrida da identidade indígena contemporânea nos permite pensar a identidade como mecanismo de representação cultural, da mesma forma como proposto por Stuart Hall (2011), em que a identidade não é um dispositivo natural, mais forjado e reconstruído ao longo do tempo histórico, e, sendo assim, no atual momento contemporâneo de fluidez de fronteiras, os sujeitos terminam por se constituírem de identidades diversas. Não é diferente com os sujeitos indígenas.

O novo projeto identitário indígena aparenta ir em direção ao apelo da tradição ancestral, motivo marcante em suas textualidades, por exemplo, ao mesmo tempo em que busca imbricar-se aos cambiantes deslocamentos, circulações e reterritorializações oferecidos pelo contato com outras alteridades não ameríndias, colocando em questão o modelo preconizado e arraigado no imaginário nacional do sujeito indígena como "condenado" a um passado estático, sempre primitivo e inapto para tecer relações culturais com outras sociedades. Para Janice Thiél, é pelo intercruzamento e o reconhecimento de um conceito de identidade que se movimenta no passado, no presente e no porvir que podemos seguir os rastros das variadas formas que se apresentam e constituem o que podemos entender por ser indígena na atualidade:

Esse movimento continuo não significa que o sujeito passe de uma raiz a outra abandonando tudo que já fez parte de seu constructo anterior; significa que a um novo constructo são agregados elementos de outras raízes, compondo assim um sujeito com múltiplos enraizamentos e desenraizamentos. Consequentemente, uma coletividade agrega 'múltiplas carteiras de identidade,' assim como qualquer indivíduo (THIÈL, 2012, p. 119). 
Mediante isso, é pela compreensão de um conceito de identidade influenciado por uma noção de deslocamento (HALL, 2011) que podemos pensar a composição dessas novas configurações identitárias indígenas, assim como um projeto de descolonização da própria subjetividade. Para Hall (2011), a noção de deslocamento sugere uma atividade de descentramento do sujeito, em que uma certa visão consagrada de identidade que perpassa por entendê-la como algo estanque, pretensamente homogênea e ontológica é substituída por uma compreensão plural, em que identidades promovem câmbios e se retroalimentam numa relação dialética, interagindo com as diferenças presentes no caldo cultural.

É na transvaloração da imagem baseada no equívoco e na indiferença presente no projeto colonial e em sua herança posterior que um devir indígena se constitui como espaço, discurso e voz que se contrapõem aos modelos culturais estabelecidos e a uma imagem projetada sobre o indígena na sua relação com os não índios. Essa indianidade representa uma maneira de identificação entre os sujeitos e uma gama de práticas discursivas que constrói mecanismos de autorrepresentação, não somente pautados pelas implicações biológicas como cor da pele, cabelos, etc., mas, sobretudo, pelas disposições, entrelaces culturais e a subjetividade do próprio sujeito indígena. Sobre isso, esclarece Florêncio Almeida Vaz Filho:

A Constituição Federal de 1988 não coloca critérios de identidade indígena, apenas estabelece a competência do Estado em demarcar as terras dos povos indígenas e garantir os seus direitos básicos. O Brasil promulgou em 2004 a Convenção 169 da OIT, que garante ser a consciência da identidade indígena ou tribal o critério fundamental para definir quem são os indígenas, apesar de que esse direito da auto-identificação indígena é desrespeitado sistematicamente pelo próprio Estado [...] (VAZ FILHO, 2011, p. 3, sic).

Nesse sentido, essa outra perspectiva possibilita entender a configuração da identidade indígena distante de uma compreensão que o enquadra como um elemento "selvagem" ou "aculturado", por exemplo, e a coloca inserida em um processo de etnogênese em que o foco central para a construção de sua identidade são as disposições e imbricações no 
plano social e na construção da própria afirmação dos indivíduos indígenas como sujeitos históricos sob suas próprias perspectivas.

Para Boccara (2001), a etnogênese é uma noção fundamental para o entendimento do processo de modificações e constituição identitárias indígenas, pois embarca em sua acepção uma perspectiva que rompe com categorias dicotômicas de representação destas identidades, tais como o conceito de aculturação ou mesmo uma posição etnocêntrica da história, permitindo pensar a outridade ameríndia como possibilitadora de diferenças.

Ainda conforme Boccara (2005), a etnogênese constitui processos complexos de integração e reformulação identitária indígena que desarticulam velhos essencialismos que colocam os ameríndios em categorias puras ou originais a sofrerem desagregação espontânea ou forçada ao longo do tempo, substituindo sua cultura ou sendo desarticulados com o contato com culturas exógenas. Para o autor, pensar em um verdadeiro fluxo de identidades se retroalimentando em espaços fronteiriços é o que permite uma flexibilidade epistêmica necessária à possibilidade de alocar o elemento cultural como fator fundamental na tentativa de projetar uma ciência direcionada ao entendimento dessas comunidades e comprometida em ouvir outras lógicas e cosmologias.

Obviamente tais contatos não são de todo harmônicos ou livres de enfrentamentos. São devidamente permeados "por negociações e conflitos" (PAIVA, 2015, p. 154) e se constituem como uma forma de resistência, sobretudo no campo das subjetividades. Somente por meio da recusa de um estado de subjetividade fadado ao simulacro seria possível promover o deslocamento dos corpos, dos afetos e dos sujeitos para um estado de devir.

Assim como destaca Michel Foucault (2014), nos resta pensar e proliferar imagens de um outro mundo de (im) possibilidades, em que o imperativo ético seja rejeitar formas de individualidade mercantilizadas ou estereotípicas e investir em forças de resistência que subvertem tal ordem, que explodem em novas cartografias.

\section{Conclusão}


Muito embora as injustiças históricas, físicas, legais, linguísticas, etc. cometidas contra os povos indígenas ainda sejam substrato para uma visão generalizada e incompleta, não há possibilidade de um paradigma intercultural se não houver quebra de hierarquias e padrões discriminatórios. Para o antropólogo José Mauricio Arruti: "[...] a etnogênese [...] é a construção de uma autoconsciência e de uma identidade coletiva contra uma ação de desrespeito" (2006, p. 51).

Dessa forma, com o avanço de autores indígenas como Olívio Jekupé, Daniel Munduruku e Eliane Potiguara, por exemplo, no campo da produção intelectual, há a reivindicação e a luta pela conquista de espaço para outros atores sociais, assim como a proliferação de outros jogos de linguagem. Essa forma de apropriação e ressignificação que se opera em campos diversos, desde os espaços consagrados até a produção do saber, passando pela efetivação dos dispositivos e agenciamentos institucionais (legais, educacionais, literários, políticos, etc.), se prolifera como mecanismo de resistência e inventividade de outros padrões de inteligibilidade, de outras formas de poder-saber.

\section{Referências bibliográficas}

ALMEIDA, Maria Regina Celestino de. Os Índios na História do Brasil. Rio de Janeiro: Editora da FGV, 2010.

ARRUTI, José Maurício. Indianidade: etnogêneses indígenas. In: Povos indígenas no Brasil. São Paulo: Instituto Socioambiental, 2006.

BARTH, Fredrik. Grupos Étnicos e suas fronteiras. In.: POUTIGNAT, Philippe; STREIFF-FENART, Jocelyne (Org.). Teorias da Etnicidade. São Paulo: Editora da Unesp, 2011. p. 25-67.

BAUDRILLARD, Jean. Simulações e simulacros. Lisboa: Relógio D’Água, 1991.

BOCCARA, Guillaume. Mundos Nuevos en las Fronteras del Nuevo Mundo. Nuevo Mundo Mundos Nuevos, Paris, v. 1, n. p., 2001. 
Génesis y estructura de los complejos fronterizos euro-indígenas: repensando los márgenes americanos a partir (y más allá) de la obra de Nathan Wachtel. Memoria americana, n. 13, p. 21-52, 2005.

BOSI, Alfredo. Dialética da colonização. São Paulo: Companhia das Letras, 1992.

BRIGHENTI, Clovis Antonio. Povos indígenas em Santa Catarina. Etnohistória, História Indígena e Educação: contribuições ao debate. Porto Alegre: Pallotti, 2015.

BRASIL. Constituição da República Federativa do Brasil. Brasília: Senado Federal, 1988.

CAMINHA, Pero Vaz de. A carta de Pero Vaz de Caminha: reprodução fac-similar do manuscrito com leitura justalinear, de Antônio Geraldo da Cunha, César Nardelli Cambraia e Heitor Megale. São Paulo: Humanitas, 1999.

CANDIDO, Antonio. Iniciação à literatura brasileira: resumo para principiantes. São Paulo: Humanitas/FFLCH/USP, 1999.

CARNEIRO DA CUNHA, Manuela. Ensaios. Rio de Janeiro: Cosac e Naify, 2009.

CRUZ, Carlos Henrique; RESENDE, Maria Leônia de. Encontros e desencontros: os povos indígenas no Novo Mundo colonial. In: RESENDE, Maria Leônia Chaves de (Org.). Mundos Nativos: Cultura e História os povos indígenas. Belo Horizonte: Fino Traço, 2015. p. 51-106.

DE MELLO, Laura et al. Inferno Atlântico. São Paulo: Companhia das Letras, 1993.

DUSSEL, Enrique. 1492: O encobrimento do Outro (ou origem do "mito da modernidade"). Petrópolis: Vozes, 1993.

FOUCAULT, Michel. O sujeito e o poder: Genealogia da Ética, Subjetividade e Sexualidade. São Paulo: Forense Universitária, 2014. (Coleção Ditos e Escritos, 9).

GÂNDAVO, Pero de Magalhães. Tratado da Terra do Brasil: História da Província Santa Cruz. Belo Horizonte: Itatiaia, 1980.

GLISSANT, Édouard. Introdução a uma poética da diversidade. Juiz de Fora: Editora UFJF, 2005.

GUZMÁN, Tracy Devine. Native and national in Brazil: indigeneity after independence. North Carolina: UNC Press Books, 2013.

HALL, Stuart. Identidades culturais na pós-modernidade. Rio de janeiro: DP\&A, 2011.

KARNAL, Leandro. Os textos de fundação da América: a memória da crônica e alteridade. Idéias, Campinas, v. 11, n. 1, p. 9-14, 2004. 
LEOPOLDI, José Sávio. Rousseau-estado de natureza, o "bom selvagem” e as sociedades indígenas. ALCEU, v. 2, n. 4, p. 158-172, 2002.

MELLO e SOUZA, Laura de. Inferno atlântico. São Paulo: Companhia das Letras, 1993.

MIGNOLO, Walter. La idea de América Latina: La herida colonial y laopción decolonial. Barcelona: Gedisa, 2005.

MUNDURUKU, Daniel. O banquete dos deuses. São Paulo: Global, 2009.

O caráter educativo do Movimento Indígena brasileiro (1970-1990). São

Paulo: Paulinas, 2012.

ORLANDI, Eni Pulcinelli. Terra à vista: discurso do confronto - velho e novo mundo. Campinas: Editora Unicamp, 2008.

PAIVA, Adriano Toledo. Entre dois mundos: saberes nativos e a contribuição dos povos indígenas a cultura brasileira. In: RESENDE, Maria Leônia Chaves de (Org.). Mundos Nativos: Cultura e História os povos indígenas. Belo Horizonte: Fino Traço, 2015. p. 145-194.

POUTIGNAT, Philippe; STREIFF-FENART, Jocelyne. Teorias da etnicidade: seguido de grupos étnicos e suas fronteiras de Fredrik de Barth. São Paulo: Editora da UNESP, 2011.

QUIJANO, Anibal. Colonialidade do poder, eurocentrismo e América Latina. In: LANDER, Edgardo (Org.). A colonialidade do saber: eurocentrismo e ciências sociais. Buenos Aires: CLACSO, 2005. p. 227-278.

RAMOS, Alcida Rita. O índio hiper-real. Revista Brasileira de Ciências Sociais, São Paulo, v. 28, n. 10, p. 5-14, 1995.

SANTOS, Luzia Aparecida Oliva dos. O percurso da indianidade na literatura brasileira: matizes da figuração. São Paulo: Cultura Acadêmica, 2009.

SHOHAT, Ella; STAM, Robert. Crítica da imagem eurocêntrica. Rio de Janeiro: Cosac Naify, 2006.

TERENA, Marcos. "Posso ser o que você é, sem deixar de ser quem sou!" In: RAMOS, M. N.; ADÃO, J. M.; BARROS, G. M. N. (Org.). Diversidade na educaçãa: reflexões e experiências. Brasília: MEC/SEMTEC, 2003. p. 99-104.

THIÉL, Janice. Pele silenciosa, pele sonora: a literatura indígena em destaque. Belo Horizonte: Autêntica, 2012. 
VAZ FILHO, Florêncio Almeida. Identidade Indígena no Brasil hoje. 2011. Disponível em: http://www.alasru.org/wp-content/uploads/2011/12/25-GT-Flor\%C3\%AAncioAlmeida-Vaz-Filho.pdf . Acesso em: 16 jul. 2015.

VIVEIROS DE CASTRO, Eduardo B. A autodeterminação indígena como valor. Anuário Antropológico, Rio de Janeiro, n. 81, p. 233-242, 1983.

Recebido em: 15/09/2015 * Aprovado em: 03/11/2015 * Publicado em: 31/12/2015 